\title{
THE HAND OF THE PLANT POTTER: A STIGMA OF THE MARKET GARDENER
}

BY

\section{HENRY COHEN}

From the Department of Medicine, University of Liverpool

(RECEIVED FOR PUBLICATION, SEPTEMBER 17, 1946)

Since the days of Hebra and Joseph Bell the detection of a man's occupation from visible signs of disease has had a singular fascination for the clinician. This note adds another occupational stigma, hitherto unrecorded, to those already recognized.

A man of 59 had been a market gardener for over thirty years. An attack of influenza in 1926 was followed by migratory rheumatic pains of moderate severity, which had interfered with his work but little until a few months before he consulted me in July, 1946. He then showed arthritic changes practically limited to the hands, a not infrequent infirmity in market gardeners, which is attributable to the local exposure to damp. In place, however, of the common finding in arthritis of the hands of ulnar deviation at the metacarpo-phalangeal joints, there was in his right index finger $30^{\circ}$, and in his left $25^{\circ}$ of ulnar deviation at the proximal interphalangeal joint (fig. 1). Radiographs of the hands (fig. 2) show clearly this arthritic change and the associated lateral subluxation. The explanation is evident from fig. 3 . An important part of a market gardener's work is the potting of plants. This entails pressing the soil down with the thumbs and fixing the pot with the index fingers; thus, pressure is applied to the radial side of the distal phalanges of the index fingers, and in joints weakened by arthritis the deformity described readily occurs. There was no accompanying hyperkeratosis.

Where, in established disease, unusual signs are found, the possibility of their being an expression of the patient's employment must always be investigated.

Fig. 1.- Hands showing arthritis (note swelling of wrists and of interphalangeal joints of the right ring and little fingers and the left middle finger) and the ulnar deviation (right $=30^{\circ}$, left $=25^{\circ}$ ) at the proximal inter$\mathrm{p}$ h a l a n ge a 1 joints of the index fingers.

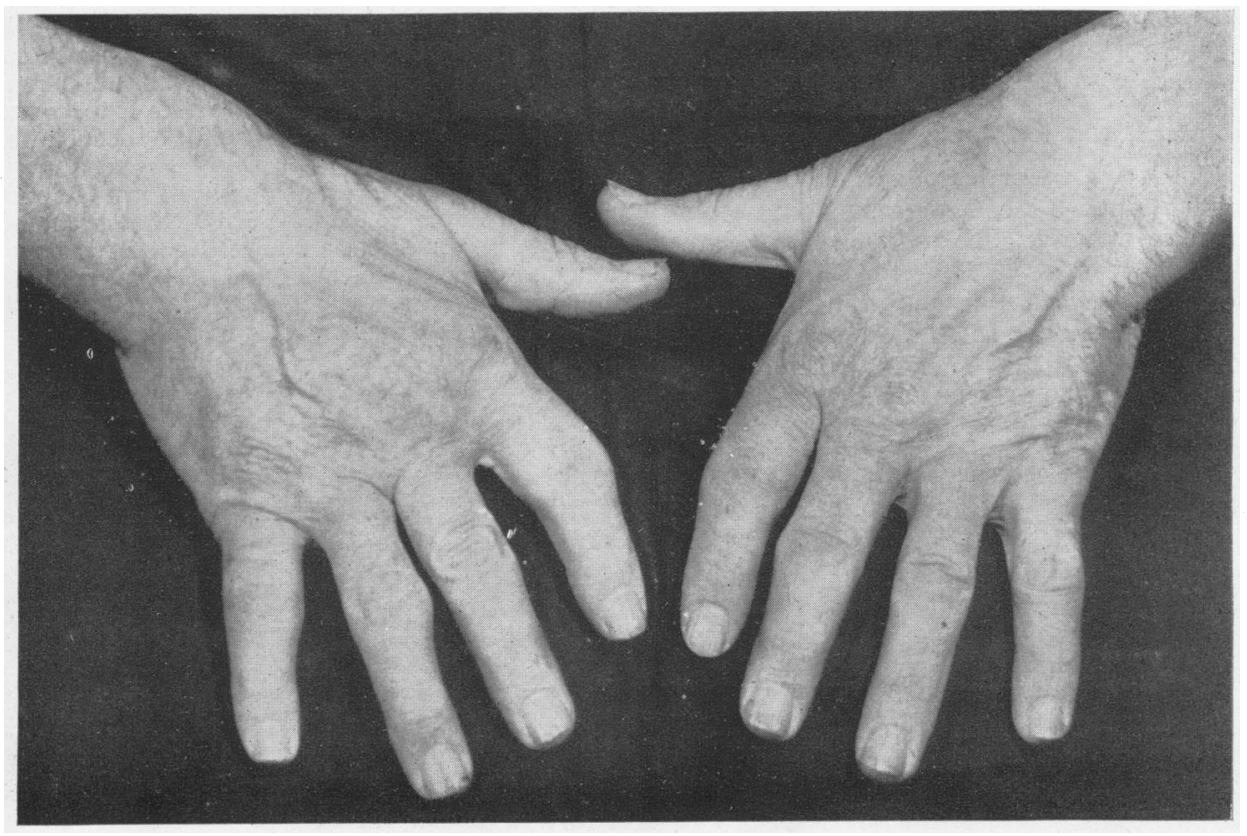




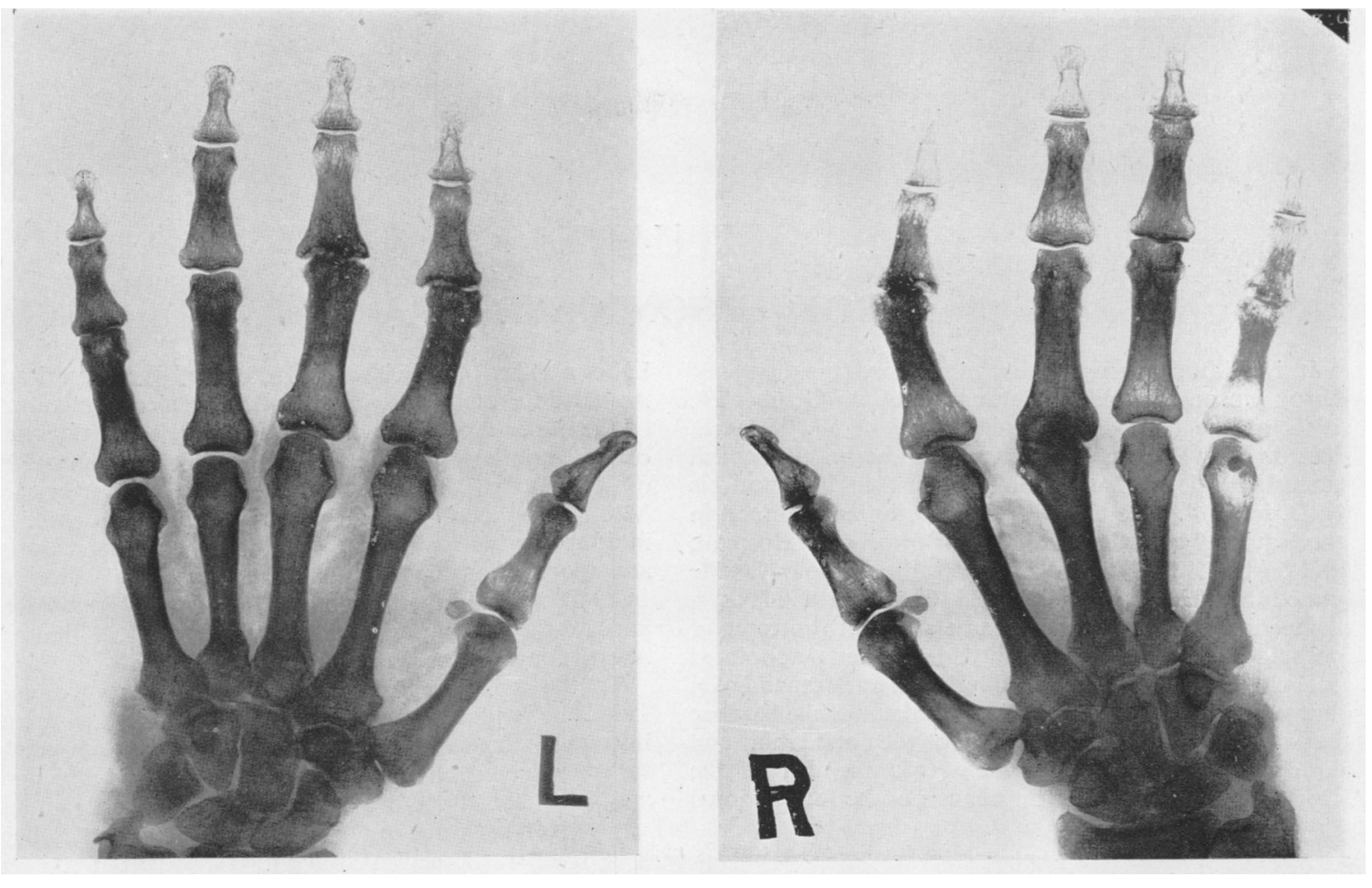

Fig. 2.-Radiographs showing arthritic changes and subluxation in the deformed joints.

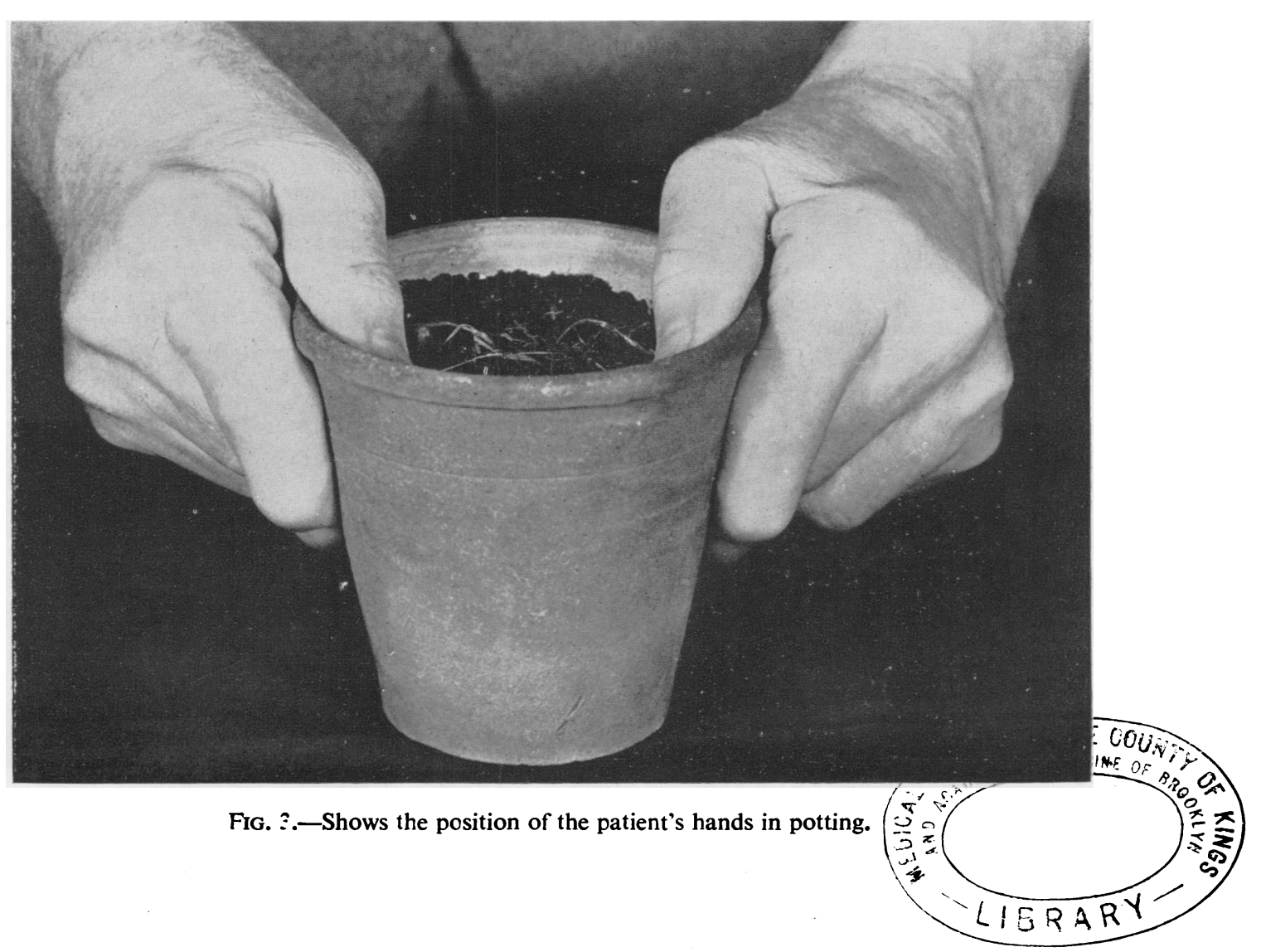

